PRAXIS

ecucativa

Universidad Nacional de La Pampa

Facultad de Ciencias Humanas

Instituto de Ciencias de la Educación

para la investigación interdisciplinaria

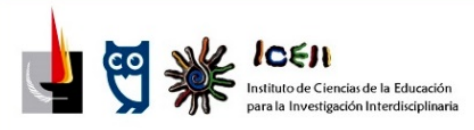

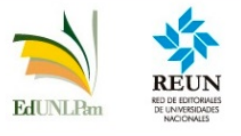

ISSN 2313-934X

SANTA ROSA, LA PAMPA, ARGENTINA

Correo electrónico: iceii@humanas.unlpam.edu.ar

Disponible en https://cerac.unlpam.edu.ar/index.php/praxis

Querer ser docente en tiempos de fobia conservadora: perspectivas de estudiantes de un profesorado del Partido de San Martín. Artículo de Eduardo Langer y Jonathan Andrés. Praxis educativa, Vol. 25, No 3 septiembre - diciembre 2021. E - ISSN 2313-934X. pp. 1-16. https://dx.doi.org/10.19137/praxiseducativa-2021-250305

Esta obra se publica baja Licencia Creative Commons 4.0 Internacional CC BY- NC-SA Atribución, No Comercial, Compartir igual

(c)

\title{
Querer ser docente en tiempos de fobia conservadora: perspectivas de estudiantes de un profesorado del Partido de San Martín
}

Wanting to be a teacher in times of conservative phobia: perspectives of students from a faculty of the San Martín

Querer ser professor em tempos de fobia conservadora: perspectivas de alunos de um corpo docente do Partido San Martín

\section{Eduardo Langer}

Universidad Nacional de San Martin

Consejo Nacional de Ciencias y Tecnología, CONICET

Argentina

langereduardo@gmail.com

ORCID: 0000-0001-7946-7129

\section{Jonathan Andrés}

Instituto de Formación Docente Nº 174

Universidad Nacional de San Martin

Argentina

andresjonathane@gmail.com

ORCID:0000 - $0001-8554-4434$

Recibido: 2021-04-07 | Revisado: 2021-08-09 | Aceptado: 2021-08-09 


\section{Resumen}

Este artículo describe los significados que adquiere el trabajo docente en contextos precarios desde el punto de vista de estudiantes de un profesorado de San Martín. La hipótesis es que, en condiciones sociales de incertidumbre para el trabajo docente, esta actividad se convierte en una opción para desafiar discursos y prácticas conservadoras que profundizan las desigualdades sociales y educativas. El estudio se desarrolla mediante un enfoque metodológico cualitativo exploratorio. Se utilizan entrevistas en profundidad realizadas desde 2018 hasta la actualidad. Las entrevistas se realizaron a estudiantes de primer y cuarto año del curso de formación. Algunos de los resultados indican que los deseos de los estudiantes con respecto a la enseñanza se producen para responder a la necesidad de hacer algo por el lugar que habitan. Eso incluye el deseo de cambio social, de obtener algún tipo de reconocimiento social y de poder transmitir conocimientos que permitan a los alumnos de la escuela ser felices u olvidar por unos momentos la tristeza cotidiana.

Palabras claves: trabajo; docencia; desigualdad social; formación.

\section{Summary}

This article describes the meanings teaching work acquires in precarious contexts. The meanings are taken from the point of view of a group of students of a teacher training program in San Martín. The hypothesis is that within social conditions of uncertainty for the teaching work, this activitty becomes an option to challenge conservative discourses and practices which deepen social and educational inequalities. The study is developed through an exploratory qualitative methodological approach. It uses in-depth interviews carried out since 2018 to the present. The interviews were made to first- and fourth-year students of the training course. Some of the results indicate that students desire regarding teaching are produced to respond to the need of doing something for the place they inhabit. That includes the desire of social change, to get some kind of social recognition, and to be able to transmit knowledge which may allow school students to be happy or to forget for a few moments the daily sadness.

Keywords: job; teaching; social inequality; training.

\section{Resumo}

Este artigo descreve os significados do trabalho docente em contextos precários na visão de alunos de um corpo docente do Partido San Martín. Ter-se-á como hipótese que, nas condições sociais de incerteza do trabalho docente, hoje é uma opção não só formar mas apostar neste trabalho como terreno que possibilita a resposta a práticas e discursos que, em tempos de fobia conservadora, aprofundam as desigualdades sociais e educacionais. 0 estudo é desenvolvido por meio de uma proposta metodológica qualitativa exploratória por meio de entrevistas em profundidade realizadas de 2018 até a presente data com alunos do primeiro e quarto ano do corpo docente. Alguns dos resultados que se apresentam indicam que os seus desejos em relação ao ensino são produzidos para responder a uma necessidade, de fazer algo pelo lugar onde vivem, mudar algo, ter algum tipo de reconhecimento e poder transmitir conhecimentos para que os alunos possam ficar felizes ou esquecer por um momento as tristezas do dia-a-dia.

Palavras-chave: trabalho; ensino; desigualdade social; formação. 


\section{Introducción}

En los últimos años, la educación pública ha sido objeto de múltiples agravios, no solo desde el plano discursivo gubernamental explícito, siendo unas de sus últimas manifestaciones la expresión de que hay quienes tienen la desgracia de caer alli, ${ }^{i}$ sino también a través de la desarticulación de programas y la eliminación de reparticiones en el Ministerio de Educación (Becerra, 2017). Ello es acompañado por un lugar cada vez más importante para los intereses del sector privado en la definición de la política educativa en detrimento de la participación de docentes y estudiantes (Feldfeber et al., 2018; Vior y Rodríguez, 2012).

Este desprestigio y desvalorización se hace extensivo al trabajo docente (Iglesias, 2019), ya que son identificados como los únicos responsables por la calidad y los resultados educativos (Becerra, 2017). Tal como dice Birgin (2015):

La construcción de un discurso que posiciona a los docentes en un lugar de no saber, de debilidad o de imposibilidad pedagógica, tiene consecuencias en los modos como se configura públicamente el valor de la tarea docente y sus contribuciones a la educación de las nuevas generaciones. (p. 9)

Estos han sido blanco de injurias y estigmatizaciones que los colocan como personas de bajos recursos y capital cultural, que han fracasado al querer realizar otras carreras, y que copan el aula con una militancia política que debe ser denunciada (Hayon, 2020).

Así, todo el problema educativo queda reducido a una cuestión de enseñanza. Con relación a esto, Birgin y Pineau (2015) afirman que la llegada de estudiantes de nuevos sectores sociales a los profesorados dio lugar a un discurso, originado en los 90 y que se sostiene hasta nuestros días, que instaló a este hecho como uno de los causantes del "deterioro de la calidad del sistema educativo" (p. 59).

En este marco, este artículo busca describir los sentidos sobre el trabajo docente en contextos precarizados desde la mirada de estudiantes que se están formando en profesorados del Partido de San Martín. Se sostendrá como hipótesis que, en condiciones sociales de desigualdad, incertidumbre, adversidades y precarización en general (Castel, 2014), y del trabajo docente en particular, hoy, para muchos, es una opción no solo concurrir a los profesorados para formarse, sino que, fundamentalmente, apuestan por esta labor como un terreno que habilita la contestación a discursos y prácticas de corte conservador que profundizan las desigualdades. En vez de la negación, los y las estudiantes en formación activan respuestas y disputan sentidos a través de la inventiva y la creación para apostar por la enseñanza en particular y por la educación en general.

Tal como nos detendremos, los y las estudiantes de los profesorados le otorgan sentidos a su formación como perspectivas a futuro, que si bien están signadas por la incertidumbre (Langer y Machado, 2013) no decantan linealmente en el inmovilismo, sino que hay "esperanzas, deseos, sueños y proyectos aún en condiciones que no dejan lugar para ello" (Langer, 2018, p. 21). Desde estas perspectivas, la docencia se sucede como una profesión que, si bien no garantiza una serie de condiciones materiales debido a los procesos de precarización laboral que encuentran su expresión en salarios insuficientes y condiciones de trabajo adversas, habilita un campo para el despliegue 
del ejercicio de luchas y acciones contra prácticas y/o racionalidades estatales (Foucault, 2007) que, desde la mirada de ellos y ellas, son definidas como el producto de una ausencia del Estado en materia de política social y escolar. Por tanto, aquí la interrogación será pensar el contexto actual más bien como resultado de un proceso de cambio hacia nuevas dinámicas de gobierno que suponen nuevas racionalidades y tecnologías de gobierno (Rose, 2007; Grinberg, 2008). En efecto, nos preguntaremos por qué la docencia es un trabajo viable en un contexto de precariedad laboral, qué sentidos se le otorga al trabajo docente en tiempos de desigualdades y bajo qué construcciones se sortean las adversidades en sus formaciones en momentos donde la fragmentación socioeducativa (Prévôt Schapira, 2002) hace esplendor y las estrategias de gobierno alientan el emprendedurismo que suponen una sobrecarga que recae sobre la comunidad educativa, y especialmente sobre los y las docentes.

Para ello, nos detenemos en los sentidos de quienes están estudiando para ser docentes. Estos sentidos aquí son considerados no como individuales o personales, sino que, tal como sostiene Deleuze (1994), son las emisiones de las singularidades, verdaderos acontecimientos trascendentales, y que presiden la génesis de los individuos y de las personas. Aquí, nos detenemos en los desplazamientos de los sentidos (Barthes, 1981), es decir, en sus dinámicas específicas en los profesorados que expresan las creencias personales y generales sobre el trabajo y la formación docente en tiempos de precarización, desigualdad y/o exclusión social. .i De esta forma, el estudio se desarrolla a través de una propuesta metodológica cualitativa exploratoria; esto es, la realización de entrevistas en profundidad a estudiantes de primer y cuarto año de un profesorado del Partido de San Martín que se vienen realizando desde el 2018 hasta la actualidad. Dicho partido es parte de la Región Metropolitana de Buenos Aires, la cual se conforma por múltiples asentamientos precarios y villas donde la precarización de la existencia y la extrema pobreza se conjuga con una marcada degradación ambiental (Curutchet et al., 2012). Es en este contexto donde los y las estudiantes se forman para ser docentes, y ellos y ellas llevan adelante su trabajo, así como también, en ocasiones, es a la vez el suelo que habitan.

La estructura de este artículo está dividida en dos apartados. El primero de ellos tiene como fin introducir ciertos elementos conceptuales que contextualizan la problemática de la fobia conservadora (Foucault, 2007) en el marco actual, los modos en que esta se vincula y adquiere caracteres específicos en las sociedades de gerenciamiento (Grinberg, 2006), así como también las conjugaciones que tienen lugar entre la gubernamentalidad (Foucault, 1991), la responsabilización de los individuos y la posición asignada a la educación en relación con el querer ser docente. El segundo apartado está dirigido a caracterizar las voces de estudiantes de un profesorado en vistas de dar cuenta de los sentidos que otorgan a su formación y al trabajo docente ante los embates que sufren estudiantes, docentes y la escuela misma desde los discursos conservadores y las prácticas políticas, económicas y sociales que estos han impuesto. Finalmente, se cierra con algunas reflexiones finales acerca de los principales resultados expuestos. 


\section{La docencia en la era de la fobia del gerenciamiento}

Una de las transformaciones destacables de fines del siglo $X X$ ha sido el pasaje de las sociedades de disciplinamiento a las sociedades de control (Deleuze, 1990), es decir, una mutación del capitalismo y el modelo de racionalidad estatal que, tal como sostiene Harvey (2000), transforma el modelo de acumulación fordista hacia otro de acumulación flexible. Ello supuso alteraciones en las formas que adoptó la gubernamentalidad (Foucault, 1991; Popkewitz, 1996), dando lugar a lo que Grinberg (2006) denomina las sociedades de gerenciamiento. A lo largo de este siglo, se fueron configurando nuevas lógicas de la gubernamentalidad neoliberal (Foucault, 2007) basada en una legitimidad del Estado fundamentada en el respeto a las libertades económicas como un sostén para la soberanía política, así como también del derecho público. Es decir, producen tecnologías de gobierno que han corrido la responsabilidad del Estado hacia los individuos y la comunidad, teniendo que autogestionarse su propia vida (Rose, 2007).

Simultáneamente, se refuerzan los procesos de precarización laboral y de la vida en general (Castel, 2014; Butler, 2006) no con un Estado que se ausenta ni desaparece, sino más bien que adopta nuevas posiciones y tecnologías de gobierno en la dirección de las conductas (Foucault, 2007; Grinberg, 2008; Popkewitz, 1996). Si tenemos en cuenta que, tal como afirma Grinberg (2008), "la intervención del Estado no debería confundirse con una necesaria redistribución de la riqueza o con procesos de democratización, y mucho menos si hablamos de la agencia estatal en el marco del sistema-mundo capitalista" (p. 106), es posible entender a un Estado que activamente favorece, a través de sus políticas, la precarización y flexibilización de las relaciones laborales (Castel, 2014).

Entre las causas de la gubernamentalidad neoliberal, siguiendo a Foucault (2007), se encuentra una visión sobre el Estado cuyo carácter intrínseco es su imperialismo endógeno que lo empuja a ganar en superficie, extensión y profundidad, siendo su objetivo la sociedad civil. Desde allí, se producen los discursos de fobia, dando lugar, entre otras cuestiones, a un liberalismo dirigido a limitar las intervenciones del Estado, lo que conlleva a su disminución en pos de otorgarle mayores márgenes de acción y decisión al mercado. De este modo, se configura un tipo de gubernamentalidad específico, por tanto, un tipo de conducción y encauzamiento particular de la conducta inmersa en relaciones de poder (Foucault, 1988), que alega que lo público (sea la escuela, la formación, la docencia o cualquier otra cosa) es malo, de poca calidad, no tiene prestigio y es deficitario. Esta pretensión de direccionamiento de la voluntad se enmarca en una economía de mercado en la que deja que "la sociedad se desarrolle como una sociedad de empresa, se establece una suerte de mecanismos de intervención para asistir a quienes lo necesitaran en el momento, y sólo en el momento que lo necesitaran" (Foucault, 2007, p. 248).

Esta asistencia cobra ciertas particularidades en las sociedades de gerenciamiento (Grinberg, 2006), ya que las mismas están integradas por individuos que se vuelven responsables y autónomos, y en tanto que los problemas sociales se ven reducidos a problemas particulares. Es decir, en los problemas educativos, la responsabilidad es sobre el propio aprendizaje y la autogestión de la vida (Masschelein y Simons, 2013). Lo interesante aquí es atender a este 
movimiento particular que se produce respecto a las problemáticas sociales que demarcan nuevos actores para su resolución, los cuales son los individuos y la comunidad (Rose, 2007).

Al ser reducida a una cuestión individual, las desigualdades son explicadas a partir de la necesidad de incorporar conocimientos económicamente útiles. Está claro que la particularidad que adquieren estos discursos en nuestros tiempos da cuenta de una vuelta a la teoría y la lógica de las inversiones en capital humano (Schultz, 1972), ahora reconvertida en competencias (Grinberg, 2008). Esta teoría posee un lugar destacable en los procesos mencionados, no solo porque "en el fondo consiste en tratar de reintroducir el trabajo dentro del campo del análisis económico" (Foucault, 2007, p. 257), sino que, además, esta habilita delinear que las diferencias en las retribuciones se corresponden con diferencias en el grado de educación (Schultz, 1972), por lo que los individuos tendrán que invertir en sí mismos de tal modo de favorecer la adquisición de aquellas competencias que promuevan su empleabilidad (Masschelein y Simons, 2013).

Ahora bien, las lecturas del capital humano se conjugan sin duda con la gubernamentalidad neoliberal donde, según Foucault (2007), cada quien se vuelve empresario de sí mismo en término de inversiones e ingresos, a la vez que "hacia esos aspectos se orientan las políticas económicas, pero no sólo ellas, sino también las políticas sociales, las políticas culturales y las políticas educacionales" (p. 273). Es un tipo de gubernamentalidad que, en el marco de las sociedades del gerenciamiento, producen la autonomización y responsabilización del individuo sobre su propia vida, a través de las lógicas del empowerment (Grinberg, 2008), y debiendo este tomar parte activa en conjunto con la comunidad, para mejorar su situación, siendo el rol del Estado "ofrecer la infraestructura para la automovilización y las oportunidades para invertir en capital humano" (Masschelein y Simons, 2013, p. 7), así como también facilitar otros recursos necesarios.

Lo problemático en estos discursos es el enmascaramiento de los procesos de precarización, desigualdad y pobreza, y no es que en otros momentos históricos no hayan existido. Tal como afirma Deleuze (1990), la miseria es una constante del capitalismo; lo particular es que los procesos mencionados bajo esta nueva gubernamentalidad cobran otra dimensión. En las sociedades de empresa, tiene lugar la producción de una población liminar (Foucault, 2007) a la cual se la pretende responsabilizar de su situación por su incapacidad de autogestionarse y hacerse empleable en contextos de incertidumbre, flexibilidad y precarización.

Así, en la gubernamentalidad de nuestro tiempo, tal como señalan Armella y Langer (2020), tiene lugar "un doble movimiento que por un lado obliga a los sujetos a autogestionar aquello que en definitiva es responsabilidad del Estado y por el otro, culpa a esos mismos actores por su mal funcionamiento o su fracaso" (p. 107). Aquí es donde los discursos del gerenciamiento cobran total particularidad y relevancia para entender los procesos sociales actuales, así como la educación en particular. Y, específicamente, hay que contextualizar la docencia y el querer ser docente en estos tiempos de fobia conservadora ya que estos procesos de autogestión y culpabilización no deben entenderse únicamente como procesos externos al sujeto porque, tal como señala Foucault (2007), la gubernamentalidad es "la manera de conducir la conducta de los hombres" (p. 218), pero esta conducción depende en gran medida de la autoregulación de los sujetos sobre sí mismos. Por tanto, 
nos encontramos que "no sólo la sociedad culpabiliza a los docentes, sino que ellos mismos, con frecuencia, se asumen responsables de procesos ajenos que terminan sin funcionar" (Armella y Langer, 2020, p. 113).

Los discursos de fobia circulan de diversas formas en nuestro pensamiento (Foucault, 2007), de modo tal que la docencia queda ajena en tanto que es objeto de gobierno y de un ejercicio político. Tanto el desprecio por lo público como por el trabajo que muchas y muchos docentes desempeñan en dichos espacios, resultan blanco de la acometida conservadora, tanto en términos de desfinanciación (Becerra, 2017) como también por la propia práctica gubernamental que deja a docentes y estudiantes librados a su suerte.

De este modo, las y los sujetos de la educación son llamados a hacerse cargo de la posibilidad de enseñar y aprender, lo que trae aparejadas consecuencias sobre el trabajo docente, ya que "las estrategias de gobierno que alientan el emprendedurismo suponen una sobrecarga de los docentes que son señalados directamente en el sostenimiento de las escuelas" (Langer y Orlando, 2018, p. 51). Dicha sobrecarga demanda un alto grado de compromiso, "exige que los docentes sean todopoderosos, versátiles y pragmáticos en la incorporación de herramientas que prometen potenciar sus prácticas" (Armella y Langer, 2020, p. 109). Pero la realidad es que los y las docentes no son todo poderosos y las carencias materiales que se sufren al interior de la escuela, así como las desigualdades que conforman nuestra sociedad, generan situaciones que los y las desbordan.

Así, aún ante esas grandes limitaciones, las esperanzas y resistencias (Ahmed, 2019) como actos políticos se tornan elementos claves para lidiar contra las fobias, los miedos y las incertidumbres, disputando la posibilidad de crear espacios y búsqueda de intersticios que implican compromisos políticos por parte de los y las docentes, así como de quienes se están formando para serlo. Con estos sentidos, la escuela se constituye, siguiendo a Armella (2018), en "ese lugar para el encuentro con otros, con lo otro, como oportunidad para la producción y circulación de la palabra, para ubicar al yo en la historia" (p. 148). La institución y los sujetos que allí están guardan un potencial en términos discursivos, así como también de prácticas hacia el interior de ese espaciotiempo y, tal como propone esta autora, tanto la vida común como la conformación de una voz colectiva son posibilidades para la disputa del lugar y del armado de las comunidades en las sociedades del gerenciamiento, donde el encuentro con los otros y con el conocimiento sea potencia para pensar y hacer un "espacio otro capaz de ir a contrapelo, como un espacio-tiempo en el que pueden suspenderse los modos de relación dominantes para construir otros nuevos" (p. 151).

Esas esperanzas, resistencias, potencias, encuentros y oportunidades implican pensar en aquello que lleva a quienes se están formando a querer ser docentes, y en la docencia en sí misma, no de una forma pasiva, sino activa, por sobre las dinámicas impuestas por los discursos conservadores que encuentran su expresión en "respuestas cotidianas a través de formas de comprometerse y de participar para sostener la escuela y disputar para que mejoren las instituciones y los procesos de enseñanza y aprendizaje" (Langer y Orlando, 2018, p. 57); entre estas tensiones y contradicciones, se desenvuelve la labor docente y, por supuesto, el deseo de serlo. Es 
decir, entre ser absolutamente responsables de los procesos educativos desde los discursos gerenciales que dicen que deben adoptar una actitud resiliente frente a la adversidad, y debiendo volverse cada docente "un líder, motivador, orientador del auto-aprendizaje" (Grinberg, 2013, p. 93), pero que, al mismo tiempo, por medio de sus discursos y prácticas, las y los docentes se ponen al hombro a sus estudiantes y a la escuela, sosteniendo cotidianamente la escolaridad en situaciones de vulnerabilidad. Ante estas tensiones descritas, cabe preguntarnos por lo sentidos que le dan los y las estudiantes de los profesorados a su formación, tanto por el gerenciamiento que atraviesa sus vidas en general, así como también por las connotaciones específicas que adquiere en la escuela y el trabajo docente.

\section{De la ausencia regulada a la posibilidad de la presencia: la perspectiva de quienes se están formando}

Como hemos mencionado previamente, han sido múltiples los cambios que han tenido lugar en el siglo XX. Entre ellos, aquí se focaliza la atención en la descripción del modo de comprender el trabajo y específicamente la formación, así como el ejercicio de la docencia, dado que han comenzado a distanciarse de una idea vocacional para acercarse a la idea de un ejercicio profesional de la educación (Birgin y Pineau, 2015). Tal como desarrollaremos, ello implica, desde la visión de quienes se están formando, asumir de otro modo no solo las políticas educativas, sino también los compromisos que ocupa la docencia en relación con el Estado y la sociedad. Tal como señala Southwell (2013), "tradicionalmente, la construcción social de la identidad de los docentes había estado vinculada a nociones como apóstoles, regidos por la vocación" (p. 1). Sin embargo, hoy, ello ya no sucede tal como pasaba en décadas anteriores. Una de las estudiantes entrevistadas da cuenta de este movimiento:

No tengo vocación, no siento que haya nacido para algo. Pienso que, si yo soy una profesional, espero ser bien paga y trabajar en condiciones, y no porque tengo vocación me pones en una plaza un banco y un pizarrón iii y tengo que remontar eso con el alma porque 'yo nací para esto'. (Estudiante, mujer, 29 años, 2020)

Tener o no tener vocación, nacer o no nacer para ser docente, ser o no una profesional, estar bien paga o no, trabajar en condiciones o no, tener alma o no para este tipo de trabajo; son todas cuestiones nodales las que plantea la estudiante en el marco de la pandemia en relación con el ser docente hoy. La estudiante confronta y disputa los sentidos que se juegan en los medios acerca de qué es la escuela pública, qué representa, quiénes son los docentes hoy y cómo son vistos por el conjunto social. Allí, se expresa gran parte de las fobias que los discursos conservadores expresan al respecto de la educación y de la docencia hoy. Esta condición de pensarse como docentes trabajadores se produce en conjunto con cambios que experimentó y experimenta la propia formación docente, ubicada hace décadas en el eje de la tormenta y de los debates que focalizan en las carencias y aquello que no tienen los y las profesores/as; pensada en un principio como una profesión dirigida a la transmisión, reproducción y producción de cultura al servicio de los 
incipientes estados capitalistas, las y los docentes han adoptado un posicionamiento crítico respecto a su función cultural (Navarro, 2015).

Dicho posicionamiento no se agota en distanciarse de los discursos reproduccionistas y tecnicistas que reducen el trabajo docente a la ejecución de aquello definido por el Estado como lo legítimo a ser transmitido, sino que también conlleva a posicionarse incluso contra el propio Estado debido a que, inmerso en las nuevas prácticas de gobierno, "se vuelve indolente, perezoso, displicente e inerme frente a las necesidades" (Langer y Orlando, 2018, p. 56). En el marco de este régimen gubernamental que promueve el emprendedurismo, el gerenciamiento y la capitalización de la vida (Masschelein y Simons, 2013), los y las estudiantes del profesorado dan sentido a las prácticas estatales, tal como sosteníamos al principio, a través de su ausencia e indiferencia frente a los múltiples procesos que afectan negativamente la vida de las personas: "Hay un Estado, un ministerio, ausente a una realidad que se plasma en la escuela" (Estudiante, varón, 52 años, 2018);

Veo bastante ausencia del Estado con lo que es educación. Hay un montón de escuelas que no tienen nada, hay muchas falencias, la maestra tiene que llevar un ventilador, la maestra lleva un caloventor si tienen frío, la misma maestra es la que tiene que salir al barrio a buscar a las familias y preguntar por qué los chicos no están yendo. (Estudiante, mujer, 29 años, 2020)

Ambos se refieren a un Estado ausente, al no contar con recursos, a las falencias, por un lado, y a la gestión de las y los maestros y maestras para suplir esas ausencias y falencias por otro. A modo de tensionar estos discursos, es posible entender que "no es el estado el que asegura y regula directamente la vida de los sujetos, pero tampoco se trata de un estado que se retira y desaparece" (Bussi et al., 2013, p. 2). Ante las lógicas del empowerment, los sujetos quedan obligados a autogestionarse y autoorganizarse la propia vida en territorios hiperdegradados, lo que se materializa en una vida mediada por la lucha por los recursos.

Por ello, docentes y estudiantes abandonados a su propia suerte deben sortear una serie de dificultades que exceden a lo estrictamente escolar, pero que, al mismo tiempo, conforma a su cotidiano en la escuela. El afrontar estas cuestiones demanda compromisos y solidaridades que se ponen en juego cotidianamente para mejorar algo de aquello que afecta a sus vidas. En relación con ello, uno de los entrevistados tensiona al máximo frente a estos discursos que expresan un Estado que regula su propia desregulación y que especula con que sea la propia comunidad que pueda dar respuestas a través de la construcción de una escuela, un espacio en el barrio, tal como él lo dice:

Yo estoy en un asentamiento, pero para el plano de San Martín es un baldío, pero hay mucha gente. Bueno, ahí la idea es implementar una escuela para adultos de primaria, con mis compañeros venimos trabajando hace cinco años habilitando un espacio. (Estudiante, varón, 52 años, 2018)

En dicho fragmento, es posible observar el modo en que se conjugan los procesos de marginación, precarización e invisibilización, siendo los propios sujetos quienes, bajo una lógica gerencial, deben sortear las dificultades creando su propio espacio educativo para dar respuesta a 
una necesidad; allí, se conjugan y profundizan las desigualdades sociales y educativas. A la vez, se atiende al deseo de poder hacer algo por el lugar en que se habita, en este caso, llevar adelante una acción para construir un espacio educativo en el barrio, que encontraría su materialidad en una escuela donde puedan asistir quienes viven allí, apostando por la educación y la docencia como un modo de dar respuesta a necesidades sobre las cuales el Estado no llega o bien ha regulado su desentendimiento. Producto de la necesidad y de la demanda, el estudiante, a pesar de su edad avanzada para los estándares sociales de formarse como maestro, comienza a estudiar para formalizar su posibilidad de estar allí. Entre esas contradicciones y tensiones, entre un tipo de gubernamentalidad en las que se apela para que cada quien deba hacerse cargo de sí mismo delegando responsabilidades a la comunidad y prácticas que se producen para dar lugar a la posibilidad, se desarrolla la formación y los sentidos de quienes se están formando para ser docentes en barrios donde las desigualdades se profundizan.

Ahora bien, aquí, sostenemos que es posible observar esas prácticas de gobierno con la pretensión de dirigir las voluntades de esas determinadas formas a la que, también, es viable atender a los puntos de fuga que se generan en esta pretensión de direccionamiento. Aún ante condiciones adversas, quienes se forman para la docencia comienzan a tensar y oponerse, siendo estudiantes, a los discursos conservadores que focalizan en las carencias, los déficits y las responsabilidades, a través de los sentidos que le dan a su formación en perspectiva de su futuro ejercicio profesional, tal como lo menciona otra estudiante: "No voy a dejar esta carrera porque sé que hay muchos chicos y muchas cosas que se pueden cambiar y creo que se puede" (Estudiante, mujer, 18 años, 2018).

No es menor que hable de cambio y de que cree que se puede. Son dos nociones que se vienen instalando social y políticamente hace ya varios años en Argentina. En 2018, el "sí se puede" y "el cambio" son los lemas de las políticas de gerenciamiento en su máximo y explícito esplendor. Sin embargo, en contraposición o con otras lógicas a estos discursos, la estudiante considera que la labor docente se perfila como una actividad que potencialmente puede transformar la realidad y no solo reproducir relaciones de desigualdad. Entre estas argumentaciones, el relato expresa el potencial de cambio como uno de los sentidos que puede motivar a muchas personas a elegir la carrera docente como su profesión. Los futuros docentes y las prácticas que llevan adelante en el aula y fuera de ella, junto con los y las estudiantes, no solo equivalen a reclamar derechos fundamentales (Langer, 2017), sino que involucran procesos en los que ellas y ellos pueden encontrar múltiples sentidos a la experiencia escolar cotidiana, tanto como poder pensar que es posible que alguien del barrio pueda tener una vida diferente a la que es instalada por el pesimismo de los medios de comunicación. Ello lo remarcaba otra estudiante entrevistada en relación con las implicaciones y obstáculos para verse y sentirse diferente a las situaciones y contextos inmediatos, tal como ella lo decía: "es raro y asombroso para los y las estudiantes y sus familias que su profesora sea del barrio". (J. Andrés y E. Langer, comunicación personal, 2 de octubre de 2020).

De este modo, querer ser docente en la escuela y el aula de hoy se constituye en términos de contención del otro, dentro de los cuales puede tener lugar algo muy diferente a lo que sucede 
por fuera, donde el sufrimiento por la desigualdad que tiene lugar en el barrio puede ser expresado y dotado de un sentimiento de lucha y esperanza, siendo clave para ello el lugar que ocupan los y las docentes en el territorio. En relación con esto, una de las estudiantes expresaba su deseo de poder habilitar a sus alumnos otras experiencias distintas a la tristeza que tienen lugar en sus cotidianos, estableciendo a la enseñanza como fundamental para ello:

Que sean felices, por lo menos el tiempo que están en la clase. Que aprendan lo que trato de enseñarles, y que por lo menos esas cuatro horas que se olviden un poquito de todas esas tristezas o de todo eso que vivieron; que se lleven un poquito de alegría. (Estudiante, mujer, 46 años, 2018)

Las y los estudiantes de los profesorados perfilan su futuro profesional como un campo de posibilidades donde la escucha, el reconocimiento y el acompañamiento del otro no puede estar escindido de las prácticas de enseñanza. Así mismo, estas prácticas operan en un horizonte de sentidos donde los fuertes procesos de precarización, desigualdad y pobreza son visibilizados. La futura docente habla de la felicidad, de la alegría, del olvido de la tristeza y que aprendan lo que les enseña en ese marco. Este deseo y esperanza que plantea la estudiante del profesorado expresa la necesidad de resistir, siguiendo a Ahmed (2019), por medio de la lucha política, a la idea misma de que nuestra mayor responsabilidad sea velar por nuestra felicidad, "lo que significa que resistirnos a la idea de que nuestra propia resistencia responda a nuestra incapacidad de cumplir con nuestra responsabilidad de ser felices" (p. 173). En tiempos de crisis, "el lenguaje de la felicidad resulta aún más influyente" (Ahmed, 2019, p. 30), como un modo en que deben tener lugar las emociones. Esas promesas de y por la felicidad (Ahmed, 2019) se expresa en discursos de autonomía que sin duda oculta la desresponsabilización y la desidia cotidiana y que ha hecho de la libertad de mercado su fuente de legitimidad (Ezcurra, 1998). Quizás un poco como crítica y otro poco como disputa y desafío de la práctica que ejercerán en el futuro, las y los estudiantes entrevistadas/os expresan deseos de compromiso y reconocimiento donde la preocupación por el bienestar de los otros resulta una cuestión central:

Me gustaría que ellos [en referencia a sus futuros alumnos] se acuerden de eso y digan que mi seño se preocupó porque no comí, o mi seño me escuchó porque le comenté que anoche no dormí por tal motivo, eso es lo que me gustaría llegar a ser. (Estudiante, mujer, 31 años, 2018)

La estudiante está hablando de lo que quiere llegar a ser como docente, dando cuenta de un deseo por comprometerse y acompañar las situaciones que generen sufrimiento en sus alumnos. Así, ellas y ellos, las y los estudiantes del profesorado, asumen sentidos y disputan contra los discursos conservadores porque no quieren ser gobernados de esas formas, tampoco quieren aceptar esas formas de regulación porque son injustas o esconden una ilegitimidad. Esas no aceptaciones, creemos, son una crítica al gobierno realizada por los sujetos. Esas formas de ser son "un rechazo a las abstracciones de la violencia económica e ideológica que ignoran quiénes somos individualmente" (Foucault, 1988, p. 6). La respuesta a la pregunta por el "¿quiénes somos?" (Foucault, 1991, p. 60) implica, justamente, un cierto rechazo a los procesos de violencia cotidiana 
que viven quienes estudian para ser profesores y profesoras, así como aquellos que saben que serán sus estudiantes en los barrios a los que nos referimos.

Asumiendo las pocas y pobres garantías que les ofrece la sociedad para su vida, con la amenaza del desempleo y la pobreza extrema propia de la acumulación flexible, los sentidos de los y las estudiantes de profesorado habilitan un universo de posibilidades que suponen tensiones, grietas y fugas a las ideas de que la realidad no se discute ni se transforma (Langer y Machado, 2013). Desear y luchar por un mundo mejor o, como lo decía una estudiante, "un mundo que necesita ser cambiado" es parte de los sentidos que los y las estudiantes de los profesorados le dan a su formación. Al mismo tiempo, la construcción de intersticios de posibilidad no implica que con la sola voluntad de estudiantes y docentes se pueda alterar la estructura política, económica o social, allí está esa tensión constante que expresan. Así, uno de los entrevistados reconoce este límite:

No creo que yo pueda cambiarle la vida a nadie, desde ya que no, ni tampoco darle a un niño las posibilidades que no tuvo en tres generaciones de familia. Pero sí creo que uno puede dar una mano, uno puede estar y apoyar, y que podemos salir a la calle a pedir mejoras. (Estudiante, mujer, 29 años, 2020)

Así, las contestaciones que pueden tener lugar no se agotan en las acciones que se llevan adelante en el aula, la escuela o el barrio, sino que, como menciona Southwell (2013), desde el retorno de la democracia y la consolidación del docente como trabajador, las lucha por mejores condiciones laborales y educativas se articula con otros discursos, algo que, desde nuestra perspectiva, por sí mismo tiende a romper con aquellas lógicas que tienden a segmentar las problemáticas sociales. Son ellas y ellos, quienes se están formando para ser docente, que se ubican entre pesimismos y optimismos, entre alegrías y tristezas, entre posibilidades e imposibilidades, entre la escuela y el barrio, entre las ausencias reguladas y las insistentes y obstinadas presencias para, como decía la estudiante del último relato, dar una mano, poder apoyar para tratar de estar mejor, y también para poder seguir enseñando.

\section{Reflexiones finales}

Ante la precarización de la vida en general y las relaciones laborales en particular, en conjunto con el emprendedurismo y autogestión que demandan las sociedades de gerenciamiento, las y los estudiantes de los profesorados ponen en juego una serie de sentidos sobre su formación, su futuro trabajo y la escuela de modos diversos y que expresan posicionamientos críticos al respecto de las fobias que los discursos conservadores producen socialmente en relación con la educación, la escuela y la docencia en particular.

Las y los que se están formando para ser maestros y maestras plantean tensiones que son ejes centrales de discusión en su formación y también en su labor futura: la idea de vocación, si se nace o se hace un docente, ser o no profesional de la educación, tener buenas condiciones laborales, entre otras. Quizás, todos los reclamos y disputas gremiales de las últimas décadas en nuestro país allí se hacen presentes, pero aquí no nos referimos a estas disputas organizadas colectivamente, 
sino a aquellas expresadas individualmente y que, por ello, no dejan de ser colectivas dado que implican demandas, necesidades, compromisos y solidaridades que se ponen en juego cotidianamente para mejorar algo de aquello que afecta a sus vidas.

Desde los sentidos que pudimos relevar, querer ser docente es crear para responder a una necesidad, desear poder hacer algo por el lugar que se habita, poder cambiar algo y creer que se puede hacerlo, vivir aquello que sus propios estudiantes acontecen, poder transmitir saberes para que puedan ser felices u olvidar por unos instantes las tristezas cotidianas, tener reconocimiento de sus estudiantes porque hubo una preocupación y una escucha. En definitiva, querer ser docente es creer que algo puede mejorar en la vida de esos niños y adolescentes. Allí disputan lo que para ellas y ellos son las ausencias de un Estado que ha regulado su desentendimiento del bienestar de la población y de las escuelas, y de lo que sucede en las aulas y en los barrios aún en situaciones tal como la que se viene viviendo hace más de un año en el que la educación a distancia se instala como lógica de escolaridad por la pandemia generada por el COVID-19.

La escuela, la formación y el trabajo docente son esos lugares desde el cual las y los estudiantes para la docencia responden a las fobias que circulan, dando cuenta de que el presente y el futuro puede ser transformado, de que es posible soñar con una sociedad diferente donde la desigualdad pueda ser, aunque difícilmente erradicada, al menos menguada desde su propio trabajo como docentes. Allí, se suceden las solidaridades, los compromisos, las responsabilidades hacia los otros, pero también unas luchas cotidianas que sin ser colectivamente organizadas no dejan de ser de suma importancia para el desarrollo de las escolaridades en las escuelas emplazadas en contextos de pobreza urbana.

Las y los estudiantes creen, desean, luchan y resisten contra los pesimismos que implican el "no se puede hacer nada". En ello se les va la vida, así como sus apuestas por su formación, por su trabajo en el aula y por las posibilidades que abre la escuela como un espacio donde lo diferente puede acontecer y los destinos precarios e inexorables impuestos se pueden alterar.

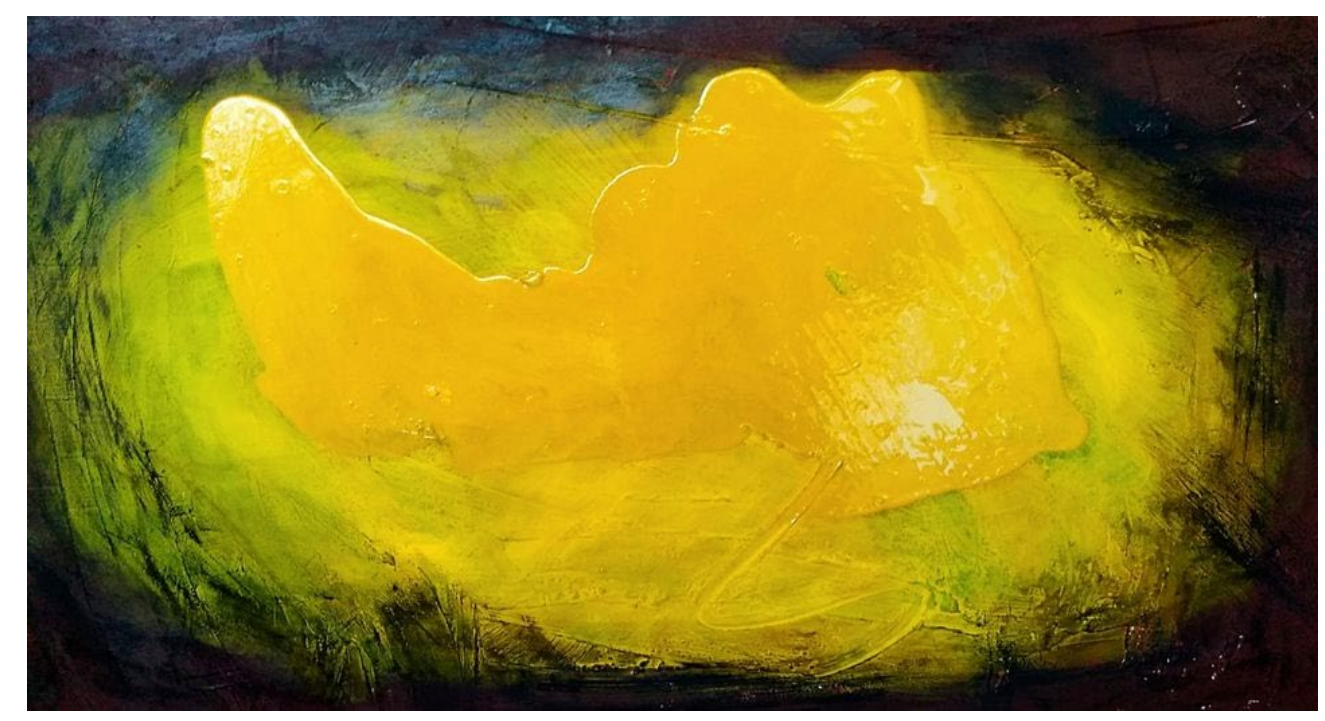

Nochevieja, acrílico. Matías Sapegno 


\section{Notas}

${ }^{1}$ Ver Página 12. (21 de marzo de 2017). "Caer" en la educación pública. https://www.pagina12.com.ar/27018caer-en-la-educacion-publica

${ }^{1}$ Aquí, se incluye la noción de exclusión social en tanto que, siguiendo a Rodríguez Guerra (2002), ningún individuo queda en algún momento por fuera de la sociedad, sino que cada uno posee diferentes grados de conexión social, así como también la dicotomía "adentro-afuera" que implica el concepto de exclusión no da cuenta de las diferencias y desigualdades que tienen lugar hacia el interior de estos polos. Solo para ejemplificar, según Grinberg y Schwamberger (2020), en las escuelas de educación especial se da lugar a lo abyecto de lo abyecto, a los excluidos de la exclusión, procurando que "sus estudiantes tengan lugar y transiten la escolaridad de manera segura y estable" (p. 7). Aquí, atenderemos a esos "adentros y afueras" siempre complejos y que adquieren múltiples expresiones, no pudiendo ser leídos únicamente en términos individuales, sino que siempre poseen un carácter colectivo.

${ }^{1}$ Este comentario tiene lugar ante la propuesta del gobierno de llevar adelante las clases en plazas debido a la situación sanitaria provocada por el COVID-19.

\section{Bibliografía}

Ahmed, S. (2019). La promesa de la felicidad. Una crítica cultural al imperativo de la alegría. Caja Negra. Armella, J. y Langer, E. (2020). De la ilusión al desencanto: sentidos y críticas en torno a la inclusión digital. Un estudio con docentes de escuelas secundarias emplazadas en contextos de pobreza urbana. Espacios en blanco. Revista de educación, 30(1), 99-115.

Armella, J. (2018). Acerca de lo común. La escuela y los muchos. Cinco líneas y una fuga. Praxis educativa, 22(2), 147-159.

Barthes, R. (1981). Mitologías. Siglo XXI.

Becerra, M. (2017). Entre la "agencia de evaluación" y la "gerencia de recursos humanos". El perfil del Ministerio de Educación y Deportes de la Nación durante la gestión de Esteban Bullrich (2015-2017). Informe de investigación N 4. Universidad Nacional de San Martín.

Birgin, A. (2015). Formación de maestros(as) en América Latina: algunos problemas y perspectivas para este tiempo. Nodos y Nudos, 4(39), 29-37.

Birgin, A. y Pineau, P. (2015). Posiciones docentes del profesorado para la enseñanza secundaria en la Argentina: una mirada histórica para pensar el presente. Revista Teoria e Prática da Educação, 18(1). Departamento de Teoria e Prática da Educação da Universidade Estadual de Maringá-UEM.

Bussi E., Grinberg S. y Langer E. (2013). Sujetos que resisten y conquistan en contextos de pobreza urbana y degradación ambiental. Un estudio en torno a los dispositivos pedagógicos en barrios periféricos del Partido de San Martín. $9^{\circ}$ Encuentro de Cátedras de Pedagogía. Universidad Nacional de Córdoba, Córdoba.

Butler J. (2006). Vida precaria. El poder del duelo y la violencia. Paidós.

Castel, R. (2014). Los riegos de exclusión social en un contexto de incertidumbre. Revista Internacional de Sociología, 72(1).

Curutchet, G., Grinberg, S. y Gutiérrez, R. (2012). Degradación ambiental y periferia urbana: un estudio transdisciplinario sobre la contaminación en la región metropolitana de Buenos Aires. Revista Ambiente \& Sociedad, $X \bigvee(2)$.

Deleuze, G. (1990). Post-scriptum sobre las sociedades de control. L'Autre Joumal, (1). 
Deleuze, G. (1994). Lógica del sentido. Paidós.

Ezcurra, A. (1998). ¿Qué es el neoliberalismo? Evolución y límites de un modelo excluyente. Lugar Editorial. Feldfeber, M., Puiggrós, A., Robertson, S. y Duhalde, M. (2018). La privatización educativa en Argentina. CTERA. Foucault, M. (1988). El sujeto y el poder. En H. L. Dreyfus y P. Rabinow, Michel Foucault: más allá del estructuralismo y la hermenéutica (pp. 227-242). UNAM.

Foucault, M. (1991). La Gubernamentalidad. En Donzelot, J.; Grignon, C.; de Gaudemar J.C.; Muel, F.. Castel, R. y Fuocault, Espacios de Poder (pp. 9-26). La Piqueta

Foucault, M. (2007). Nacimiento de la biopolítica. Fondo de cultura económica.

Grinberg, S. (2006). Educación y gubernamentalidad en las sociedades de gerenciamiento. Revista Argentina de Sociología, 4(6). Miño y Dávila.

Grinberg, S. (2008). Educación y poder en el siglo XXI. Gubernamentalidad y pedagogía en las sociedades de gerenciamiento. Miño y Dávila.

Grinberg, S. (2013). Sociedad de la información, tecnologías y pedagogías de las competencias en la era del management. Hacia una genealogía. Revista Horizontes Sociológicos, 1(2).

Grinberg, S. y Schwamberger, C. (2020). Devenir escuela colador: dinámicas de escolarización de estudiantes con discapacidad en contexto de pobreza urbana de la Región Metropolitana de Buenos Aires. Praxis educativa, 24(2), 1-15.

Harvey, D. (2000). Las condiciones de la posmodernidad. Amorrortu.

Hayon, A. (17 de noviembre de 2020). Soledad Acuña contra los docentes: estigmatización y persecución. Página 12. https://www.pagina12.com.ar/306128-soledad-acuna-contra-los-docentes-estigmatizacion-ypersecuc

Iglesias, A. (2019). De "herederos y corajudos": La imagen pública de la docencia en la prensa gráfica argentina. Rev. Actualidad Investigativas en Educación, 19(2). Consultado el 20 de marzo de 2021 en https://www.scielo.sa.cr/scielo.php?script=sci_arttext\&pid=S1409-47032019000200199\&Ing=en\&nrm=iso Langer, E. y Machado, M. (2013). Estudiantes, resistencia y futuro en contextos de pobreza urbana. Polifonías, Revista de Educación, I/(2).

Langer, E. y Orlando, G. (2019). Docencia, trabajo y disputas cotidianas en escuelas secundarias de las sociedades del gerenciamiento. Revista de la escuela de ciencias de la educación, 2(14), 51-60.

Langer, E. (2017). La escuela aún es útil en una sociedad sin trabajo. Sentidos que docentes y estudiantes le dan a la formación en contextos de pobreza urbana. $13^{\circ}$ Congreso Nacional de Estudios del Trabajo. Buenos Aires, Argentina.

Langer, E (2018). Los miedos en tiempos de crisis según docentes y estudiantes de Argentina. Universitas, 28, 19-38.

Masschelein, J. y Simons, M. (2013). Se nos hacen creer que se trata de nuestra libertad: notas sobre la ironía del dispositivo de aprendizaje. Revista Pedagogía y Saberes, (38), 93-102.

Navarro, M. (2015). Cómo entender la formación docente: Concepciones y perspectivas en Argentina. Revista de educação Movimento, 2(2). Universidade Federal Fluminense.

Página 12. (21 de marzo de 2017). "Caer" en la educación pública. https://www.pagina12.com.ar/27018-caer-enla-educacion-publica

Popkewitz, T. (1996). El estado y la administración de la libertad a finales del siglo XX: descentralización y distinciones Estado/sociedad civil. En Pereyra, Garcí Minguez, Beas y Gómez (Comp.), Clobalización y descentralización de los sistemas educativos. Ediciones Pomares. 
Prévôt Schapira, M. F. (2002). Buenos Aires en los años '90: metropolización y desigualdades. Revista EURE, 28(85), 93-102. Pontificia Universidad Católica de Chile.

Rodríguez Guerra, J. (2002). La exclusión social, un problema recurrente del capitalismo. Disenso, (44).

Rose, N. (2007). ¿La muerte de lo social? Re-configuración del territorio de gobierno. Revista argentina de sociología, 5(8). Miño y Dávila.

Schultz, T. (1972). Inversión en Capital Humano. En M. Blaug, Economía de la educación. Siglo XXI.

Southwell, M. (2013). Treinta años de políticas educativas y demanda sindical docente. Cuestiones de Sociología, (9), 2013.

Vior, S. y Rodríguez, L. (2012). La privatización de la educación argentina: un largo proceso de expansión y naturalización. Revista Pro-posiçoes, 2(23). UniCamp. 